\title{
Ground Water in Certain Sites in Egypt and Its Treatments Using a New Modified Ion Exchange Resin
}

\author{
- Characterization of Water and Modified Ion Exchange
}

\author{
Nariman H. Kamel ${ }^{1}$, AlSaid M. Sayyah ${ }^{2}$, Ahmed A. Abdel-aal ${ }^{1}$ \\ ${ }^{1}$ Radiation Protection Department, Nuclear Research Center, Atomic Energy Authority, Cairo, Egypt. ${ }^{2}$ Faculty of Science at Beni-Suef \\ University, Beni Suef, Egypt. \\ Email: Narimankamel@hotmail.com
}

Received January $12^{\text {th }}, 2011$; revised February 22 ${ }^{\text {nd }}, 2011$; accepted March $29^{\text {th }}, 2011$.

\begin{abstract}
The present work is a comprehensive of drinking water quality. Eleven groundwater samples were taken from various rural regions of Egypt, the groundwater samples were investigated for chemical, radiometric and heavy metals analyses, the major cations including; sodium $\left(\mathrm{Na}^{+}\right)$, potassium $\left(\mathrm{K}^{+}\right)$, calcium $\left(\mathrm{Ca}^{2+}\right)$ and magnesium $\left(\mathrm{Mg}^{2+}\right)$ ions species, the major anions of chloride $\left(\mathrm{Cl}^{-}\right)$, sulphate $\left(\mathrm{SO}_{4}^{2-}\right)$, nitrite $\left(\mathrm{NO}_{2}^{-}\right)$, phosphate $\left(\mathrm{PO}_{4}^{3-}\right)$. Radiometric analyses in water expressed as the gross alpha and beta activity concentrations, heavy metals analyses including arsenic ( $\mathrm{As}^{3+}$ ), lead $\left(\mathrm{Pb}^{2+}\right)$, cobalt $\left(\mathrm{Co}^{2+}\right)$, manganese $\left(\mathrm{Mn}^{2+}\right)$, iron $\left(\mathrm{Fe}^{3+}\right)$ and cadmium $\left(\mathrm{Cd}^{2+}\right)$ ions. The groundwater samples were found to contain high concentrations of heavy metals than the limited values of the world health organization (WHO). Heavy metals speciation were performed using MinteqA2 geochemical code. A modified exchange resin was prepared by polymerization of the condensed dioxalayl p-sulphanilamide with phenol, this ion exchange resin was examined by the different techniques such as; $x$-ray diffraction, infra red spectra (IR), and electronic microscopic, it was found a good adsorbent material that used for the reduction of heavy metals from contaminated groundwater samples.
\end{abstract}

Keywords: Ion Exchange, Groundwater, Heavy Metals, Sorption

\section{Introduction}

Heavy metals and radionuclides can enter into surface and groundwater from a variety sources, Water pollution is thus a consumpolitan problem that need urgent attention [1-4]. large amount of heavy metals and radionuclides can introduced into water body through untreated and treated liquid wastes. The origin of heavy metals contamination in drinking water lies in the illegal disposal of industrial effluents, which eventually find their way into underground aquifers. It is expected that concentration of heavy metals in drinking water will increase and their removal will be needed a great effort in future. Various treatment have been employed to reduce heavy metals from aqueous solutions. Conventional techniques usually involve application of various process such as precipitation, filtration solvent extraction and ion exchange [5]. Cation exchange resin is to be useful for the removal small concentrations of heavy metals from aqueous solutions. A number of investigators have been used ion exchange materials for the removal of inorganic metal ions such as $\mathrm{Pb}, \mathrm{Cu}, \mathrm{Zn}, \mathrm{Cd}$ and $\mathrm{Ni}$ from aqueous solutions [5-8]. The purpose of the present study is to give characterization of groundwater samples at certain region in Egypt, and to clean up these contaminated groundwater samples that may be used for human consumer by using a synthetic ion exchange resin.

\section{Materials and Methods}

\subsection{Chemicals and Apparatus}

All chemical reagents are used in the experimental work are analytical grade. Inductive couple plasma, atomic emission spectrometry (ICP-AES) apparatus (France) is installed at the chemical laboratory, Second Research Reactor, Atomic Energy Authority, Egypt. Low back- 
ground alpha and beta detector (Sophine) apparatus is obtained from Germany, it was used for the measurements of gross alpha and beta activity concentrations in the groundwater samples. The infra-red measurements were carried out using Schimatzu FTIR-430 Jasco spectrometer (Japan) with $\mathrm{KBr}$ disk technique.

\subsection{Sampling}

The groundwater samples (1-11) are taken from different locations sited parallel to Ismailia canal water stream, and near to the Atomic Energy Authority of Egypt. Figure 1 Shows the site locations of the groundwater samples

\subsection{Chemical Analyses}

The groundwater samples are chemically analyzed for the major cations, $\mathrm{Na}^{+}, \mathrm{K}^{+}, \mathrm{Ca}^{2+}$ and $\mathrm{Mg}^{2+}$, major anions $\mathrm{Cl}^{-}, \mathrm{SO}_{4}{ }^{2-}, \mathrm{NO}_{3}{ }^{-}, \mathrm{NO}_{2}^{-}, \mathrm{PO}_{4}{ }^{3-}$, and $\mathrm{HCO}_{3}{ }^{-}$and heavy metals. $\mathrm{Co}^{2+}, \mathrm{Cd}^{2+}, \mathrm{Fe}^{2+}, \mathrm{Pb}^{2+}, \mathrm{Mn}^{2+}$ and $\mathrm{As}^{3+}$. Concentrations of $\mathrm{Na}^{+}, \mathrm{K}^{+}$ions were determined by flam photometer, $\mathrm{Ca}^{2}, \mathrm{Mg}^{2+}$ ion concentrations and alkalinity were determined by the titration method. The major anions of $\mathrm{Cl}^{-}, \mathrm{SO}_{4}{ }^{2-}$ ions species were determined using turbidimetry method. $\mathrm{PO}_{4}{ }^{3-}, \mathrm{NO}_{2}{ }^{-}$and $\mathrm{NO}_{3}{ }^{-}$were also determined using colourmietric method [9]. All heavy metals concentrations were analyzed using inductive coupled plasma atomic emission spectroscopy (ICP-AES).



Figure 1. The site location of the groundwater samples with the code no. (1-11). Note: AEA is the Atomic Energy Authority. 1. Shibin Al-Qanater. 2. Kafr Hamza. 3. Seriaqos. 4. Masaken Abu-Zabal. 5. Menia Shiha. 6. Tal Bani-Tamim. 7. Al-Sahafa. 8. Al-Khanka. 9. El-Munyer. 10. Arab Guhaina. 11. Shebin Al-Qanater 2.

\subsection{Radiometric Analyses}

The groundwater samples were analyzed for the gross alpha $(\alpha)$, and gross beta $(\beta)$ activity concentrations $(\mathrm{Bq} / \mathrm{l})$, these analyses are determined using low background alpha and beta spectroscopy.

\subsection{The Modified Ion Exchange Resin Preparation}

The modified ion exchange resin is prepared in the current study by polymerization of the condensed dioxalayl p-sulphanilamide with phenol, excess of formaldehyde aqueous solution was inserted drop by drop to complete the chemical reaction. The former complex compound is prepared by the reaction of oxalic acid with sulphanilic acid using Dean and Stark apparatus (Figure 2). The following procedures (a \& b) are used to prepare this cation exchange resin.

\subsubsection{A-Preparation of Dioxaloyl Para Sulphanilamide}

Dioxaloyl para sulphanilamide is prepared using Dean and Stark apparatus, oxalic acid (2 mole) and sulphanilic acid (1 mole) are introduced in the dean and stark apparatus using xylene as a reaction medium. Water produced from condensation reaction of carboxylic group (from oxalic acid) and amino group (from sulphanilic acid) are collected in side tube in the dean and stark apparatus. After the collection of the physical quantity of water, the reaction was stopped and the solid material was formed. This reacting product was separated, filtrated from xylene, dried in an oven at $140^{\circ} \mathrm{C}$ to remove traces of $\mathrm{xy}$ lene then, it washed with warm distilled water at $40^{\circ} \mathrm{C}$ to remove the unreacted oxalic acid. Finally, this product is dried in an oven at $70^{\circ} \mathrm{C}$ till a constant weight was given

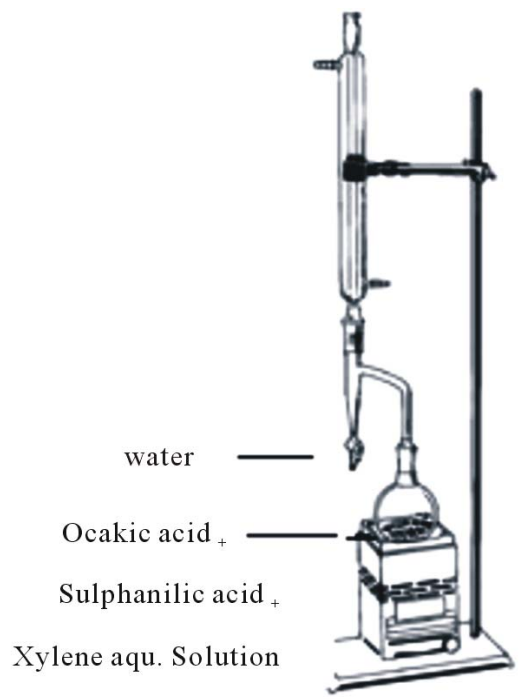

Figure 2. The dean and stark apparatus. 
The dry solid material was recrystallized from distilled water and dried (c.f. Scheme 1).

\subsubsection{B-Preparation of the Modified Phenolic Resin} $13.6 \mathrm{~g}$ of the produced crystalline solid was added to $300 \mathrm{ml}$ of acetic acid, this mixture was stirred well by a glass rod. $25 \mathrm{~g}$ of phenol was added to the mixture then $30 \mathrm{ml}$ of concentrated $\mathrm{H}_{2} \mathrm{SO}_{4}$ aqueous solution was followed by addition $67.5 \mathrm{~g}$ formaldehyde to the previouse mixture drop wisely. the mixture (exothermic reaction) was left to gain the room temperature. The produced solid was filtered and washed repeatedly to attain $\mathrm{pH}$ 7. The solid phase was separated, dried at $110^{\circ} \mathrm{C}$, grinded and sieved, the desired grain size distribution was given as adsorbent for the sorption experiments.

\subsection{Identification of the Modified Ion Exchange Resin}

The modified ion exchange resin solid material is characterized by different techniques such as Fourier Transform Infra Red (IR) Spectroscopy, X-ray diffraction and Scanning Electron Microscope

\subsubsection{Cation Exchange Capacity (CEC)}

The cation exchange capacity of the modified ion exchange resin was determined by titration method using
$0.1 \mathrm{M} \mathrm{NaOH}$ and $\mathrm{HCl}$ aqueous solutions, the exchangeable ions (meq/g) are plotted as a function of the different $\mathrm{pH}$ values [9].

\subsubsection{IR, XRD and SEM}

Approximately $1.0 \mathrm{mg}$ of the modified ion exchange resin sample was used for pellet preparation with $60 \mathrm{mg}$ $\mathrm{KBr}$, then thermal treatment of the pellets was heated in an oven at $80^{\circ} \mathrm{C}$ for 24 hours to reduce the humidity content in the sample are carried out to prevent the overlapping between water and carboxyl group bands in the spectrum. X-ray diffraction pattern of the prepared ion exchange resin as well as electronic microscopic were also examined

\subsection{Sorption Experiments}

A known weight ( 0.01 to $0.2 \mathrm{~g}$ ) of the dry synthetic ion exchange sample was shaken at $180 \mathrm{rpm}$ with a constant volume $(50 \mathrm{ml})$ of the natural groundwater sample in $100 \mathrm{ml}$ polyethylene bottles. After 24 hours, an equilibrium was attained, the solid phase was separated from the aqueous phase by centrifugation at $180 \mathrm{rpm}$ for 30 minutes. The aqueous phase of each sample was filtered and analyzed for heavy metals such as, As, Cd, Cr, Co, Fe, Mn, and $\mathrm{Pb}$ using ICP-AES. The metal ion removal expressed

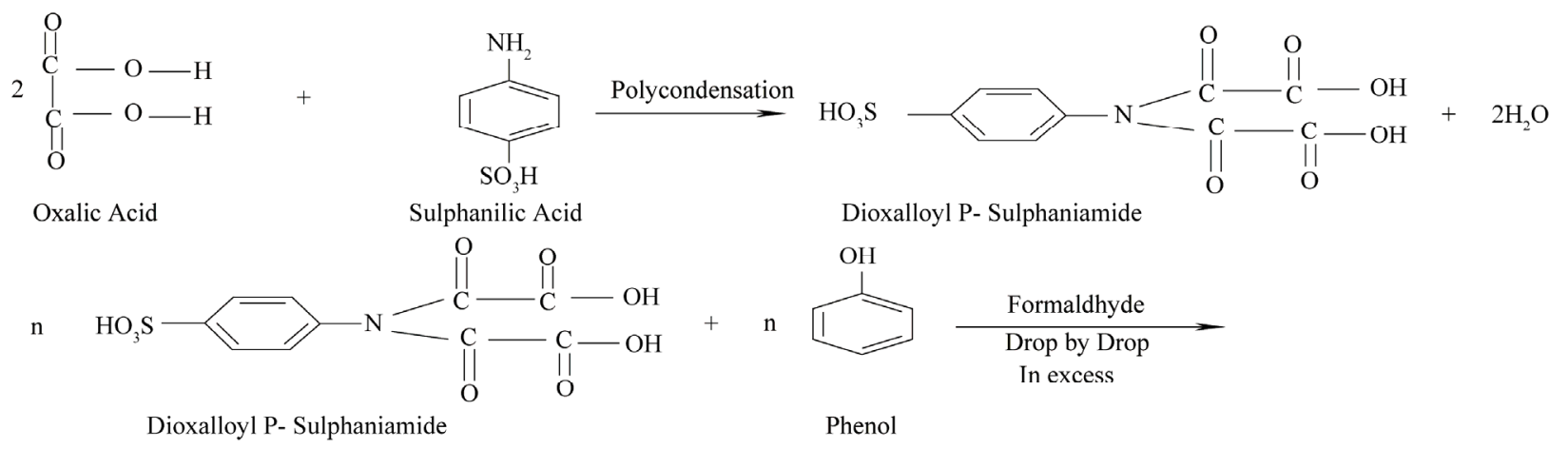

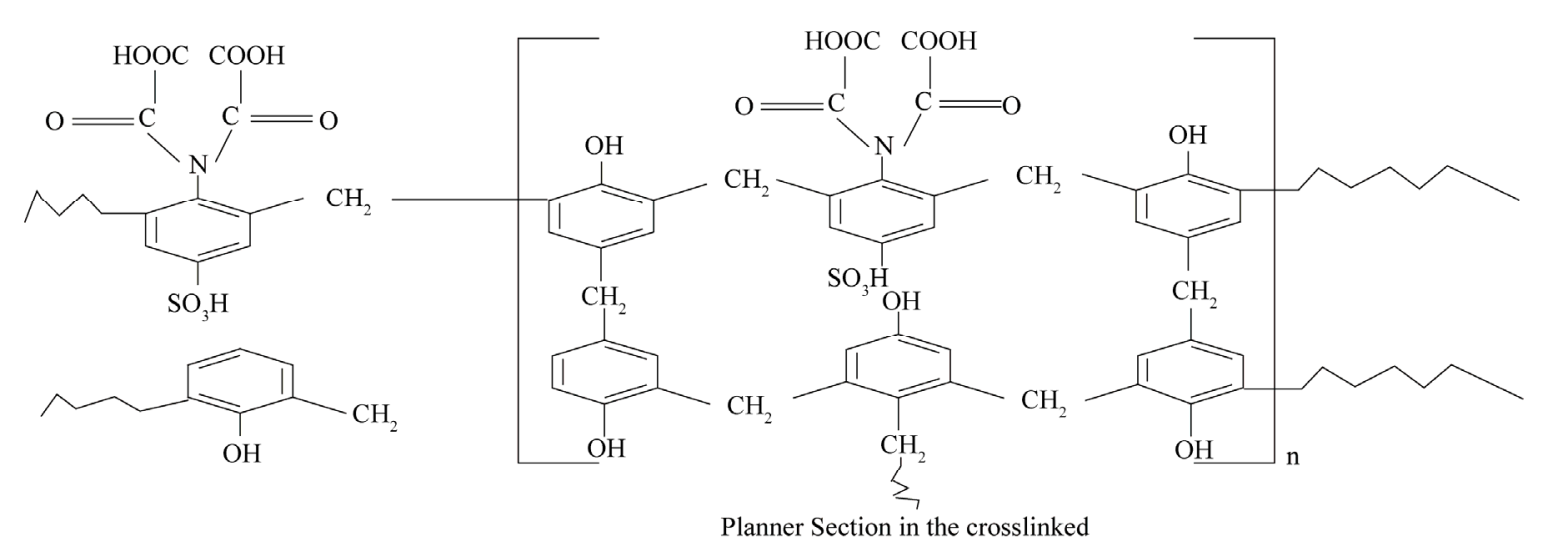

Synthesized Cation Exchange Resin Showing the Chmemical Structure

Scheme 1. The modified ion exchange resin is prepared by the condensation of Dioxalayl-P-Sulphanimide with phenol. 
as ppb, (where, $1 \mathrm{ppb}=1 / 1000 \mathrm{ppm}$ ). Concentrations of the metal ion in solution and that adsorbed on the solid phase are calculated as follows:

$$
\mathrm{q}(\mathrm{mg} / \mathrm{g})=\frac{\left(C_{0}-C\right) \cdot V}{m}
$$

and the adsorption percentage is given as:

$$
\text { Adsorption }(\%)=\frac{\left(C_{o}-C_{a q .}\right)}{C_{o}} \times 100
$$

Where, $q$ is the amount of the metal adsorbed (mg/g), $C_{o}$ is the initial metal ion concentrations, $C_{a q}$ is the final aqueous cation concentration $(\mathrm{mg} / \mathrm{l}), V$ is the solution volume by liter and $\mathrm{m}$ is the mass of the metal adsorbent (g).

\section{Results and Discussions}

\subsection{The Modified Ion Exchange Resin Characterization}

The prepared ion exchange resin has the specific surface area $5.2 \mathrm{~m}^{2} / \mathrm{g}$, hydrogen ion concentrations $(\mathrm{pH})$ is 6.8 , the specific density is $1.3 \mathrm{~m}^{3} / \mathrm{g}$ and the specific cation exchange capacities values are 1.1 and $3.0 \mathrm{meq} / \mathrm{g}$, that corresponding to the two functional carboxylic $-\mathrm{COOH}-$ and $-\mathrm{SO}_{3} \mathrm{H}-$ active groups.

The Infra red absorption bands are given in Figure 3, and their assignment are summarized in Table 1, the results show that strong absorption band appeared at $686 \mathrm{~cm}^{-1}$, it could be attributed to the bending deformation of $\mathrm{SO}_{2}$ group. The absorption band was found at $835 \mathrm{~cm}^{-1}$ may be attributed to the multisubstituted benzene ring (C-H group) out of the phase deformation. The strong absorption band appearing at $1423 \mathrm{~cm}^{-1}$ is due to the symmetric stretching vibrations for $\mathrm{CH}_{2}$ group, other strong absorption band appearing at $1601 \mathrm{~cm}^{-1}$ could be attributed to the symmetric stretching vibration for $\mathrm{C}=\mathrm{C}$ in benzene ring. The strong absorption band appearing at $1631 \mathrm{~cm}^{-1}$ is due to stretching vibration of the carbonyl group in region of $(\mathrm{N}-\mathrm{C}=\mathrm{O})$ group. The medium absorption band at $1732 \mathrm{~cm}^{-1}$ is due to stretching vibration of the carbonyl group in free carboxylic group. The broad band appearing at 3300 to $2648 \mathrm{~cm}^{-1}$ is due to the overlap of $\mathrm{OH}$ group at the sulphonic and carboxylic acid groups.

X-ray diffraction pattern indicated that the modified ion exchange resin is represented by the major amorphous structure mixed with a small portion of the crystalline structure. The electron microscopy pictures is given in Figures $\mathbf{4}$ and 5, The Scanning electron microscope of the bulk modified ion exchange resin is given in Figure 4, while Figure 5 gives the sector of this ion exchange resin, the scanning electron microscope are generally used to detect the topography of the resin grain surface and the molecules orientation in the space. From these Figures, it is clear that the prepared ion exchange resin has a micro tubular structure.

\subsection{Groundwater Samples}

\subsubsection{Physical and Chemical Parameters}

The physical and chemical parameters of the groundwater samples are given in Table 2. Conductivity is the ability of the water to conduct an electrical current, it is directly proportional to the total dissolved solids (TDS) and is an indirect measure of the ion concentration.

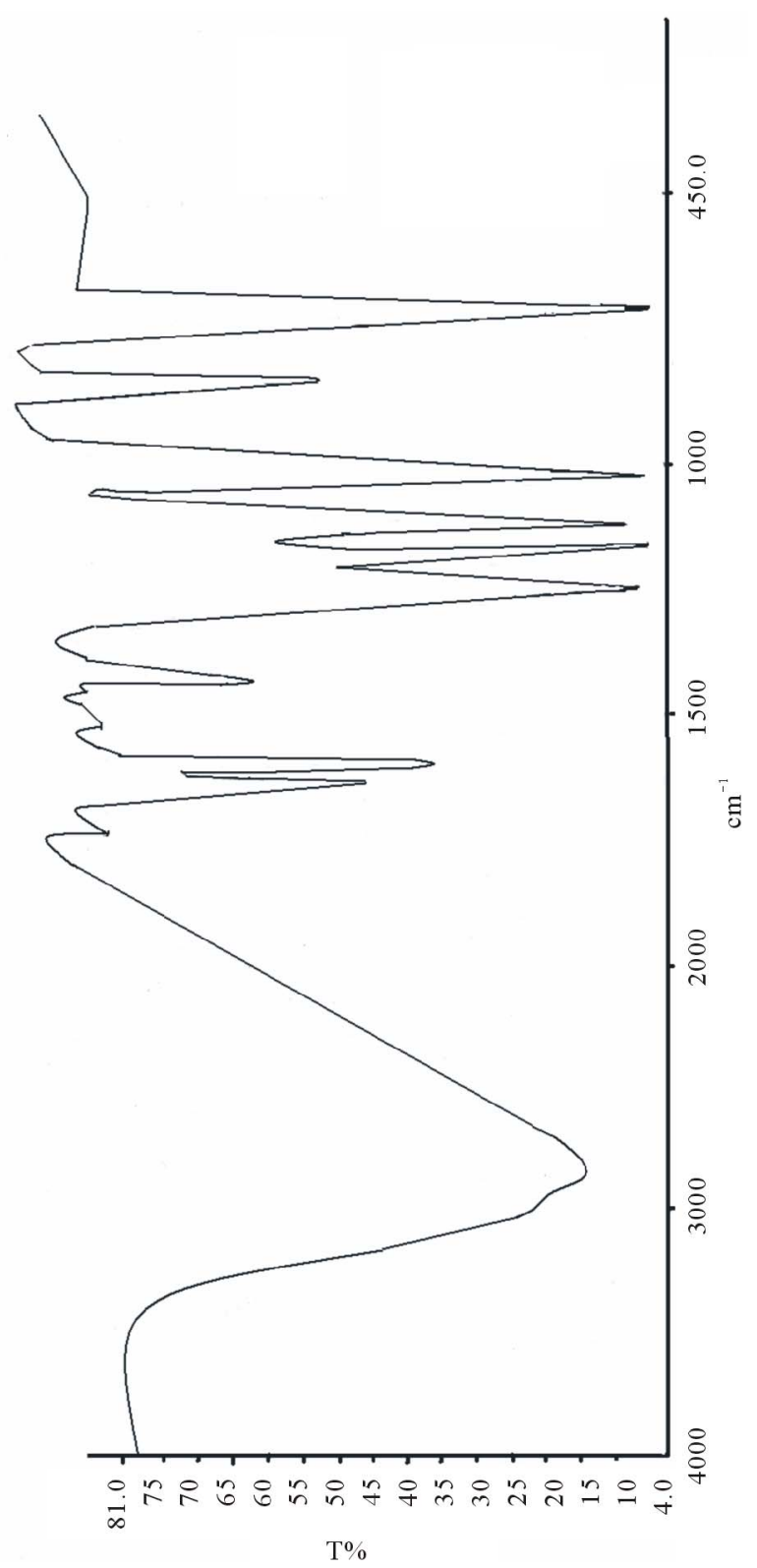

Figure 3. The infra red spectra of the modified ion exchange resin. 
Table 1. The peak assignment for each wave number $\left(\mathrm{cm}^{-1}\right)$ of the IR spectrum at the modified ion exchange resin.

\begin{tabular}{ll}
\hline Wave number $\left(\mathrm{cm}^{-1}\right)$ & Peak assignment \\
\hline $686^{\mathrm{s}}$ & Bending deformation of $\mathrm{SO}_{2}$ group \\
$835^{\mathrm{s}}$ & $\mathrm{CH}$ out of plane bending for multisubstituted benzene ring \\
$1009^{\mathrm{s}}, 1035^{\mathrm{s}}, 1167^{\mathrm{s}}$ and $1246^{\mathrm{s}}$ & Symmetric Stretching for $\mathrm{C}-\mathrm{O}$ group \\
$1423^{\mathrm{s}}$ & Symmetric stretching for $\mathrm{CH}_{2}$ group \\
$1601^{\mathrm{s}}$ & Symmetric stretching for $\mathrm{C}=\mathrm{C}$ group in benzene ring \\
& \\
$1631^{\mathrm{s}}$ & \\
& Symmetric stretching for $\mathrm{C}=\mathrm{O}$ group in \\
$3300^{\mathrm{s}}$ & Symmetric stretching for $\mathrm{C}=\mathrm{O}$ group in carboxylic group \\
\hline
\end{tabular}

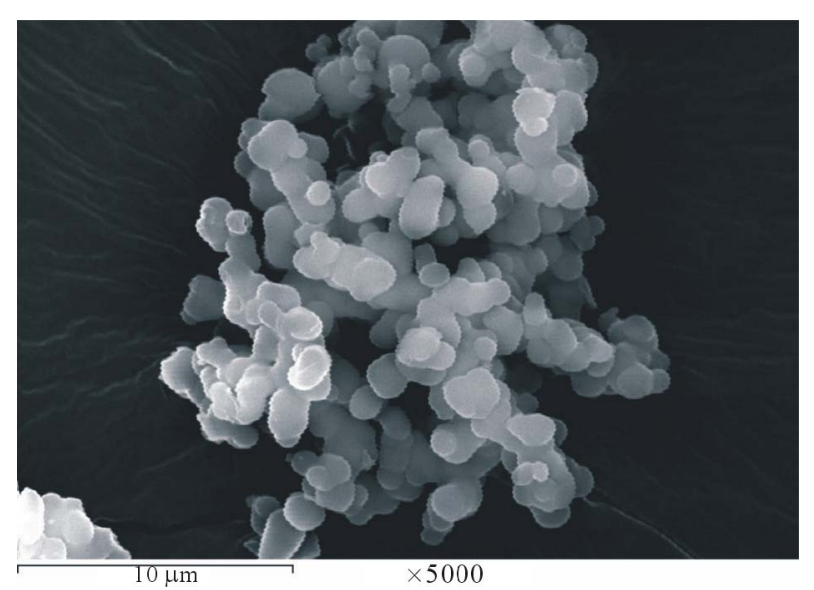

Figure 4. Scanning electron microscope of the bulk modified ion exchange resin.

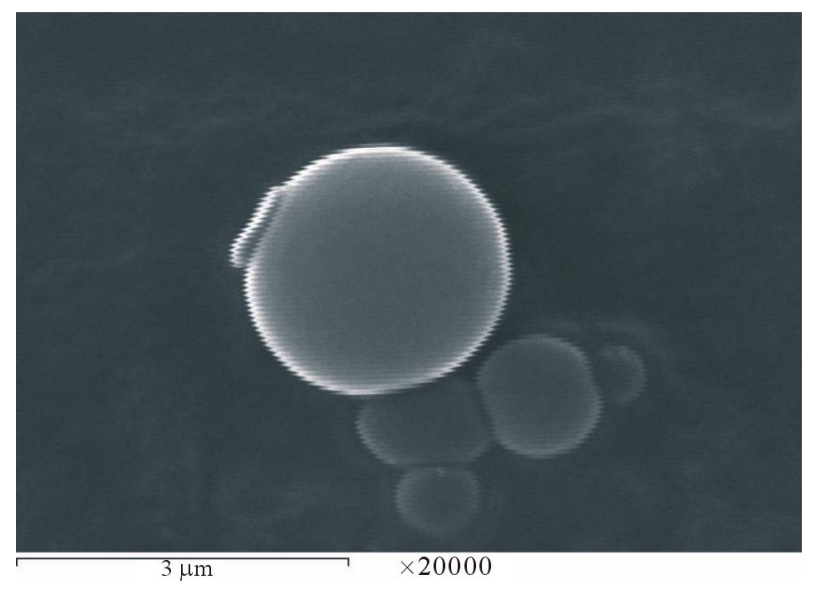

Figure 5. Scanning electron microscope sector of the modified ion exchange resin.
Table 2. The physical parameters of the groundwater samples (1-11).

\begin{tabular}{lclll}
\hline & \multicolumn{4}{c}{ Physical parameters } \\
\cline { 2 - 5 } Sample No. & $\mathbf{p H}$ & $\begin{array}{c}\text { Conductivity } \\
(\boldsymbol{\mu} / \mathbf{c m})\end{array}$ & $\begin{array}{c}\text { Turbidity } \\
(\mathbf{N T U})\end{array}$ & $\begin{array}{c}\text { TDS } \\
(\mathbf{m g} / \mathbf{l})\end{array}$ \\
\hline 1 & 7.5 & 385 & 1.54 & 222 \\
2 & 7.5 & 735 & 3.17 & 426 \\
3 & 7.5 & 536 & 2.07 & 311 \\
4 & 7.5 & 676 & 1.02 & 392 \\
5 & 7.6 & 1441 & 8.56 & 836 \\
6 & 7.5 & 1171 & 5.39 & 679 \\
7 & 7.5 & 525 & 2.35 & 305 \\
8 & 7.6 & 1215 & 2.17 & 705 \\
9 & 7.6 & 1587 & 0.68 & 920 \\
10 & 7.6 & 380 & 2.49 & 223 \\
11 & 7.6 & 300 & 2.3 & 250 \\
\hline
\end{tabular}

High concentrations values of the TDS at the groundwater samples No. 5, 6, 8 and 9 indicated by the high salt storage content at these area of the investigated samples These results may also indicated by the releasing of industrial wastes pollution at the area of these samples. The $\mathrm{pH}$ varied from 7.5 to 7.6. Concentrations of the major cations, $\left(\mathrm{Na}^{+}, \mathrm{K}^{+}, \mathrm{Ca}^{2+}\right.$, and $\left.\mathrm{Mg}^{2+}\right)$, and anions $\left(\mathrm{F}^{-}, \mathrm{Cl}^{-}, \mathrm{HCO}_{3}^{-}\right.$, $\mathrm{SO}_{4}^{2-}, \mathrm{NO}_{3}^{-}, \mathrm{NO}_{2}^{-}$, and $\mathrm{PO}_{4}^{3-}$ ) are given in Table 3 . Concentrations of the cations and anions in meq/l of the groundwater represented in Figures 6 and 7. Concentrations of the major cationic species are found to decrease 
Table 3. The major cations, anions and the charge balance error (\%) of the groundwater samples.

\begin{tabular}{|c|c|c|c|c|c|c|c|c|c|c|c|c|}
\hline \multirow{2}{*}{ Well no. } & $\mathrm{Cl}^{-}$ & $\mathrm{F}^{-}$ & $\mathrm{NO}_{3}$ & $\mathrm{NO}_{2}^{-}$ & $\mathrm{PO}_{4}^{3-}$ & $\mathrm{SO}_{4}^{2-}$ & $\mathrm{HCO}_{3}^{-}$ & $\mathrm{Ca}^{2+}$ & $\mathrm{Mg}^{2+}$ & $\mathrm{K}^{+}$ & $\mathrm{Na}^{+}$ & \multirow{2}{*}{$\begin{array}{l}\text { Ch.Ba. } \\
\text { Err. (\%) }\end{array}$} \\
\hline & \multicolumn{11}{|c|}{ (mg/l) } & \\
\hline 1 & 38.2 & 0.32 & 0.24 & 0.01 & 0.01 & 31.7 & 134.0 & 22.4 & 11.4 & 3.6 & 21.6 & -4.06 \\
\hline 2 & 76.0 & 0.38 & 0.06 & 0.68 & 0.02 & 33.6 & 270.0 & 59.9 & 21.3 & 3.6 & 25.6 & -2.64 \\
\hline 3 & 30.0 & 0.44 & 0.034 & 0.18 & 0.07 & 9.0 & 254.0 & 35.3 & 17.8 & 2.5 & 21.3 & -2.95 \\
\hline 4 & 44.0 & 0.41 & 5.60 & 0.01 & 0.20 & 68.9 & 238.0 & 57.7 & 14.2 & 5.2 & 23.9 & -4.34 \\
\hline 5 & 138.0 & 0.55 & 0.12 & 0.43 & 0.13 & 221.7 & 451.2 & 75.7 & 29.4 & 7.3 & 122.8 & -1.54 \\
\hline 6 & 157 & 0.19 & 0.73 & 0.01 & 0.05 & 81.90 & 366.0 & 77.6 & 26.3 & 5.7 & 66.5 & -4.28 \\
\hline 7 & 32.8 & 0.27 & 0.26 & 0.01 & 0.10 & 31.20 & 224.0 & 47.8 & 13.25 & 9.4 & 20.1 & -1.92 \\
\hline 8 & 128.0 & 0.68 & 26.89 & 0.06 & 0.92 & 188.5 & 344.0 & 80.4 & 80.4 & 14.9 & 59.4 & 0.08 \\
\hline 9 & 157.0 & 0.97 & 2.38 & 2.18 & 0.22 & 421.2 & 380.0 & 84.3 & 27.9 & 18.7 & 83.2 & -3.73 \\
\hline 10 & 39.0 & 0.46 & 0.35 & 0.03 & 0.15 & 31.85 & 130.0 & 1.1 & 116.1 & 22.8 & 446.1 & 1.48 \\
\hline 11 & 32 & 0.32 & 0.35 & 0.03 & 0.17 & 30.0 & 132.2 & 1.2 & 88 & 9.2 & 40 & -1.3 \\
\hline
\end{tabular}

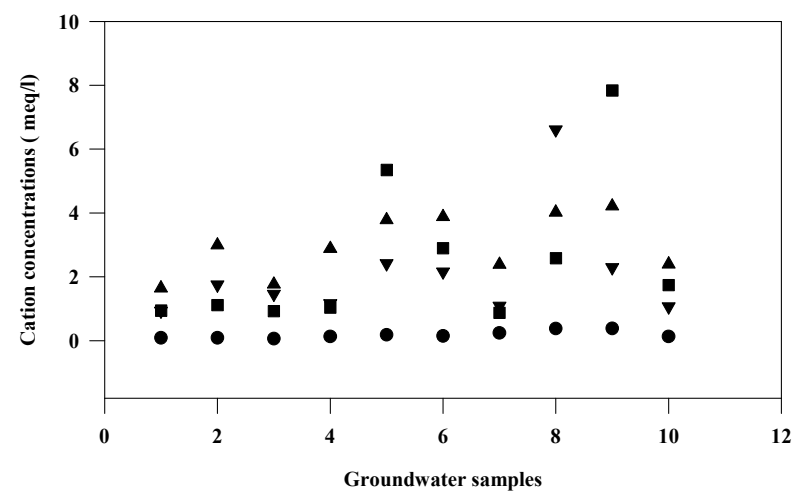

Figure 6. Cations concentrations (meq/l) of the groundwater sample (1-11). $\bullet: \mathrm{K}, \square: \mathrm{Na}, \Delta$ : $\mathrm{Ca}$ and, $\nabla: M g$ ions species.

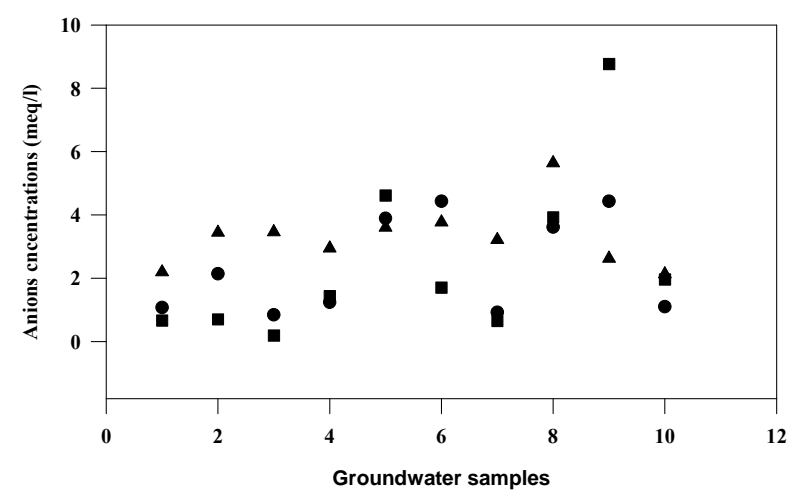

Figure 7. Anions concentrations (meq/l) of the groundwater sample (1-11). •:Cl, 匹: $\mathrm{SO}_{4}^{2-}, \boldsymbol{\Delta}: \mathrm{HCO}_{3}^{-}$.

in the following order: $\mathrm{Na}>\mathrm{Ca}>\mathrm{Mg}>$ and $\mathrm{K}$. The major cations species are sodium, and calcium ions species. these cations may be assumed found as bicarbonates mixed with the minor sulphate ions species.

The quality of the water was determined from the charge balance error (\%) factor, this factor was calculated from the major cations and anions analyses as follows [11]:

The charge balance error $(\%)=$ $\frac{\left.\sum \text { (equivalent of cations }-\sum \text { equivalent of anions }\right) \times 100}{\left.\sum \text { (equivalent of cations }+\sum \text { equivalent of anions }\right)}$

If the charge balance calculated value is less than $5 \%$, the quality of the analysis is considered in the acceptable range. these calculations required conversion factor from (mg/l) unit into (meq/l) unit. (Conversion factors from $(\mathrm{mg} / \mathrm{l}) \times \mathrm{A}=\mathrm{meq} / \mathrm{l}$, where $\mathrm{A}$ is the molar volume $=$ $\frac{1 \times \text { charge }}{\text { molecular weight }}$, this factor depending on the ionic charge and the molecular weight of the ion). The charge balance error factor of the groundwater samples are given between $1.48 \%$ and $4.34 \%$, which are within of acceptable range. Concentrations of the heavy metals (As, Cd, $\mathrm{Co}, \mathrm{Cr}, \mathrm{Fe}, \mathrm{Mn}$, and $\mathrm{Pb}$,) at the groundwater samples are also given in Table 4, the ions concentrations are compared with the standard guideline values of the world health organization [10].

Most of the groundwater samples are found to have a higher concentrations values of , $\mathrm{SO}_{4}^{2-}$, As, $\mathrm{Cd}, \mathrm{Co}, \mathrm{Pb}$, $\mathrm{Mn}$ and $\mathrm{Fe}$ ions species than was reported by the standard guideline limit values of the WHO [10], these results indicated by the releasing of pollutions in the form of bicarbonates, sulphates and/or arsenate ions species 
Table 4. Concentrations of heavy metals $(\mathrm{mg} / \mathrm{l})$ in the groundwater samples.

\begin{tabular}{|c|c|c|c|c|c|c|c|c|c|c|}
\hline \multirow{2}{*}{$\mathbf{S}$} & \multicolumn{10}{|c|}{ Heavy Metals Concentration (mg/l) } \\
\hline & Al & As & $\mathbf{C d}$ & Co & $\mathrm{Cr}$ & $\mathbf{F e}$ & Mn & $\mathbf{P b}$ & Si & $\mathbf{V}$ \\
\hline 1 & 0.39 & 0.24 & 0.02 & 0.02 & 0.01 & 0.08 & 0.11 & 0.09 & 1.66 & ND \\
\hline 2 & 0.11 & 0.23 & 0.03 & 0.01 & ND & 0.61 & 0.31 & 0.11 & 15.32 & 0.01 \\
\hline 3 & 0.09 & 0.24 & 0.03 & 0.03 & 0.02 & 0.42 & 0.47 & 0.10 & 13.46 & 0.01 \\
\hline 4 & 0.09 & 0.23 & 0.01 & 0.02 & ND & 0.27 & 0.01 & 0.11 & 6.67 & 0.01 \\
\hline 5 & 0.12 & 0.24 & 0.03 & 0.04 & ND & 0.64 & 0.31 & 0.29 & 13.52 & 0.01 \\
\hline 6 & 0.16 & 0.23 & 0.04 & 0.02 & ND & 0.78 & 0.511 & 0.13 & 19.85 & 0.01 \\
\hline 7 & 0.09 & 0.24 & 0.02 & 0.01 & ND & 0.87 & 0.14 & 0.30 & 11.64 & 0.01 \\
\hline 8 & 0.09 & 0.24 & 0.01 & 0.02 & 0.01 & 0.45 & 0.29 & 0.28 & 9.28 & 0.02 \\
\hline 9 & 0.09 & 0.24 & 0.02 & 0.02 & 0.01 & 0.08 & 0.10 & 0.14 & 13.30 & 0.06 \\
\hline 10 & 0.31 & 0.02 & 0.01 & 0.02 & 0.007 & 0.08 & ND & 0.23 & 12.91 & 0.06 \\
\hline 11 & 0.32 & 0.03 & 0.01 & 0.02 & 0.07 & 0.07 & 0.01 & 0.30 & 12.91 & 0.06 \\
\hline
\end{tabular}

$\mathrm{ND}=$ not detected

\subsubsection{Radiometric Study}

Gross alpha and gross beta activity concentrations values at the groundwater samples are summarized in Table 6. Gross alpha activity values are found between 0.02 and $0.50 \mathrm{~Bq} / \mathrm{l}$, these values are lower than the critical detection limit value $(0.5 \mathrm{~Bq} / \mathrm{l})$ that estimated by the WHO (2004). The groundwater samples have a high gross beta activity concentrations values which are lower than the maximum permitted values $(1.0 \mathrm{~Bq} / \mathrm{l})$. An increasing in the gross beta activities values at all of the groundwater samples is related to the fact of increasing the natural potassium content at the samples $\left({ }^{40} \mathrm{~K}\right.$ is emitted beta particles).

\subsubsection{Speciation of Heavy Metals in the Groundwater Samples.}

The groundwater samples (1-11) are found to contain high concentrations of $\mathrm{Pb}, \mathrm{Co}, \mathrm{Mn}$ and $\mathrm{Cd}$ ionic species, concentrations ranges of those elements are compared with the standard guideline of drinking water values. Table 5 gives the heavy metals ranges at the groundwater samples (1-11) and the limit value of the WHO (2004). Most of the groundwater samples contain low concentrations of the gross alpha and beta activity concentrations. Cadmium range $0.01-0.35 \mathrm{ppm}$, arsenic from 0.23 to $0.24 \mathrm{mg} / \mathrm{l}$, lead $0.137-0.295 \mathrm{ppm}$ and cobalt $0.150-0.93 \mathrm{ppm}$. Chromium range $0.004-0.017 \mathrm{mg} / \mathrm{l}$ is lower than the permissible limit value $0.10 \mathrm{mg} / \mathrm{l}$. Generally, the increases of heavy metals concentrations in the groundwater might be attributed to the direct input from different sources untreated and treated industrial liquid wastes and dust containing car exhaust, these metals may be diffused from the pollutants to the soil surfaces and water, then it settled in the groundwater resources [11]. The species of those ions that dissolved in the groundwater may be expressed as both free and complex compound ions species. Those ions species are calculated at the fixed $\mathrm{pH}$ value 7.6 using geochemical code Visual MinteqA2 version 2.3. the minimum and the maximum ions concentrations are used in those calculations are given in Table 5. Table 7 gives the species of the heavy metal ions percentage at the minimum ions concentrations and, Table 8 gives these species at high ions concentrations, from these Tables, it can be stated that:

- At the low ions concentrations, low ionic strength, the major of $45.32 \% \mathrm{Cd}\left(\mathrm{SO}_{4}\right)_{2}^{2-}$ and $46.68 \% \mathrm{Cd}\left(\mathrm{CO}_{3}\right)_{2}^{2-}$, 62.53\% $\mathrm{CoHCO}_{3}^{+}$, 99.89 $\mathrm{FeF}_{3}, 98.15 \% \mathrm{~Pb}\left(\mathrm{CO}_{3}\right)_{2}^{2-}$, $49.30 \% \mathrm{PbCl}_{4}^{2-}$, and $37.7 \mathrm{~Pb}\left(\mathrm{SO}_{4}\right), 31.88 \% \mathrm{MnCO}_{3}$, and $48.43 \% \mathrm{MnCl}_{3}$ ions species

- At the high ions concentrations the major of $99.80 \%$ $\mathrm{Cd}\left(\mathrm{SO}_{4}\right)_{2}^{2}, 90.06 \% \mathrm{CoSO}_{4}, 72.38 \% \mathrm{Fe}\left(\mathrm{SO}_{4}\right)_{2}^{-}$and $90.65 \% \mathrm{MnCl}_{3}^{-}$ions species are formed at the high ions species.

The removal of those heavy metals ions by the modified ion exchange resin was carried out. Table 9 gives the removal percentage. Similar results are observed at all groundwater samples. Figure 8 gives concentrations of the heavy metals ions before and after contacted with the groundwater sample 4. All arsenic ions are removed, decreasing in the heavy metal ions concentrations values are observed after contact of the groundwater samples with the modified ion exchange resin sample for 24 hours. 
Table 5. The concentrations ranges of the ionic species at the groundwater samples and the standard guideline of drinking water.

\begin{tabular}{ccc}
\hline Parameter & Standard guideline $(\mathrm{mg} / \mathrm{l})$ & Conc. $(\mathrm{mg} / \mathrm{l})$ The parameters in the groundwater samples $(1-11)$ \\
\hline $\mathrm{F}$ & 2.0 & $0.20-1.00$ \\
$\mathrm{Cl}^{-}$ & 300 & $30.0-138.0$ \\
$\mathrm{HCO}_{3}^{-}$ & 250 & $130-451.2$ \\
$\mathrm{SO}_{4}^{2-}$ & 300 & $9.0-421.2$ \\
$\mathrm{As}$ & 0.01 & $0.23-0.24$ \\
$\mathrm{Cd}$ & 0.01 & $0.01-0.35$ \\
$\mathrm{Co}$ & $\mathrm{Nil}$ & $0.15-0.93$ \\
$\mathrm{Cr}$ & 0.10 & $0.004-0.017$ \\
$\mathrm{~Pb}$ & $\mathrm{Nil}$ & $0.137-0.295$ \\
$\mathrm{Mn}$ & 0.05 & $0.10-0.51$ \\
$\mathrm{Fe}$ & 0.3 & $0.027-0.90$ \\
$\mathrm{~N}$ & $<10$ & $0.10-26.9$ \\
\hline
\end{tabular}

Table 6. The gross alpha and beta activity concentrations values $(\mathrm{Bq} / \mathrm{l})$ of the groundwater samples (1-11).

\begin{tabular}{ccc}
\hline Well No. & Gross alpha $(\mathbf{B q} / \mathbf{l})$ & Gross beta $(\mathbf{B q} / \mathbf{l})$ \\
\hline 1 & 0.17 & 0.08 \\
2 & 0.52 & 0.44 \\
3 & 0.34 & 0.03 \\
4 & Nil & 0.64 \\
5 & 0.17 & 0.19 \\
6 & Nil & 0.16 \\
7 & Nil & 0.01 \\
8 & Nil & 0.01 \\
10 & Nil & 0.17 \\
\hline
\end{tabular}

Table 7. Speciation of heavy metals of the groundwater samples at the fixed ph value 7.6 and ionic strength $<4$ using MinteqA2 code version 2.3.

\begin{tabular}{|c|c|}
\hline Metal & Component metal \% \\
\hline Cd & $\begin{array}{l}0.043 \% \mathrm{CdCl}^{+}, 7.39 \% \mathrm{CdCl}_{2}, 0.15 \% \mathrm{CdSO}_{4}, 45.32 \% \mathrm{Cd}\left(\mathrm{SO}_{4}\right)_{2}^{2-}, \\
0.21 \% \mathrm{CdCO}_{3}, 46.68 \% \mathrm{Cd}\left(\mathrm{CO}_{2}\right)_{2}^{2-}\end{array}$ \\
\hline Co & $0.029 \% \mathrm{CoF}^{+}, 0.025 \% \mathrm{CoCl}^{+}, 16.10 \% \mathrm{CoSO}_{4}, 21.31 \% \mathrm{CoCO}_{3}$ and $62.53 \% \mathrm{CoHCO}_{3}^{+}$ \\
\hline $\mathbf{F e}$ & $0.105 \% \mathrm{FeF}_{2}^{+}$and $99.89 \mathrm{FeF}_{3}$ \\
\hline $\mathbf{P b}$ & $0.36 \% \mathrm{PbCl}_{3}^{-}, 1.16 \% \mathrm{PbCl}_{4}^{2-}, 0.173 \mathrm{~Pb}\left(\mathrm{SO}_{4}\right), 98.15 \% \mathrm{~Pb}\left(\mathrm{CO}_{3}\right)_{2}^{2-}, 0.124 \% \mathrm{PbCO}_{3}$ and $0.021 \mathrm{PbHCO}_{3}^{+}$ \\
\hline Mn & $9.12 \mathrm{MnHCO}_{3}{ }^{+}, 31.88 \% \mathrm{MnCO}_{3}, 0.021 \% \mathrm{MnF}^{+}, 48.43 \% \mathrm{MnCl}_{3}^{-}, 2.34 \% \mathrm{MnCl}_{2}, 0.03 \% \mathrm{MnCl}^{+}$and $8.17 \% \mathrm{MnSO}_{4}$ \\
\hline
\end{tabular}


Table 8. Speciation of heavy metals of the groundwater samples at the fixed ph value 7.6 and ionic strength $>4$ using MinteqA2 code version 2.3.

\begin{tabular}{|c|c|}
\hline Metal & Component metal \% \\
\hline Cd & $0.15 \% \mathrm{CdCl}_{2}, 99.80 \% \mathrm{Cd}\left(\mathrm{SO}_{4}\right)_{2}^{2-}$, and $0.046 \% \mathrm{Cd}\left(\mathrm{CO}_{2}\right)_{2}^{2-}$. \\
\hline Co & $0.013 \% \mathrm{CoCl}^{+}, 90.06 \% \mathrm{CoSO}_{4}, 2.52 \% \mathrm{CoCO}_{3}$ and $7.41 \% \mathrm{CoHCO}_{3}^{+}$ \\
\hline $\mathbf{F e}$ & $0.84 \% \mathrm{FeF}_{2}^{+}, 0.032 \% \mathrm{Fe}(\mathrm{OH})_{2}^{+}, 27 \% \mathrm{FeF}_{3}$ and $72.38 \% \mathrm{Fe}\left(\mathrm{SO}_{4}\right)_{2}^{-}$ \\
\hline $\mathbf{P b}$ & $0.012 \% \mathrm{PbCl}_{2}, 3.34 \% \mathrm{PbCl}_{3}^{-}, 49.30 \% \mathrm{PbCl}_{4}^{2-}, 37.7 \mathrm{~Pb}\left(\mathrm{SO}_{4}\right), 9.59 \% \mathrm{~Pb}\left(\mathrm{CO}_{3}\right)_{2}^{2-}$, and $0.012 \% \mathrm{PbCO}_{3}$ \\
\hline Mn & $0.179 \mathrm{MnHCO}_{3}^{+}, 0.627 \% \mathrm{MnCO}_{3}, 90.65 \% \mathrm{MnCl}_{3}^{-}, 0.961 \% \mathrm{MnCl}_{2}$, and $7.58 \% \mathrm{MnSO}_{4}$ \\
\hline
\end{tabular}

Table 9. the percentage of ions removal by the modified ion exchange resin.

\begin{tabular}{|c|c|c|c|c|c|c|c|}
\hline \multirow{2}{*}{ Sample Code No. } & \multicolumn{7}{|c|}{ Removal \% } \\
\hline & As & Cd & $\mathrm{Cr}$ & Co & $\mathrm{Fe}$ & Mn & $\mathrm{Pb}$ \\
\hline 1 & 95.91 & 96.95 & 88.48 & 76.77 & 79.15 & 89.72 & 88.46 \\
\hline 2 & 99.96 & 93.47 & Nil & Nil & 85.52 & 52.14 & 92.96 \\
\hline 3 & 99.60 & 99.65 & 96.95 & 92.84 & 66.73 & 84.10 & 99.17 \\
\hline 4 & 95.94 & 87.56 & Nil & Nil & 96.33 & 69.95 & 93.58 \\
\hline 5 & 95.78 & 98.83 & Nil & Nil & 82.09 & 49.01 & 95.22 \\
\hline 6 & 96.10 & 91.54 & Nil & Nil & 84.23 & 30.71 & 88.64 \\
\hline 7 & 94.96 & 98.41 & Nil & Nil & 55.06 & 71.46 & 83.02 \\
\hline 8 & 95.84 & 98.40 & 87.05 & 86.93 & 33.56 & 31.17 & 76.07 \\
\hline 9 & 96.03 & 97.75 & 86.64 & 49.12 & 75.37 & 42.13 & 97.08 \\
\hline 10 & 95.95 & 92.89 & 11.71 & 73.09 & 70.91 & 94.54 & 97.20 \\
\hline 11 & 93.94 & 92.82 & 20.17 & 72.17 & 78.14 & 89.88 & 85.37 \\
\hline
\end{tabular}

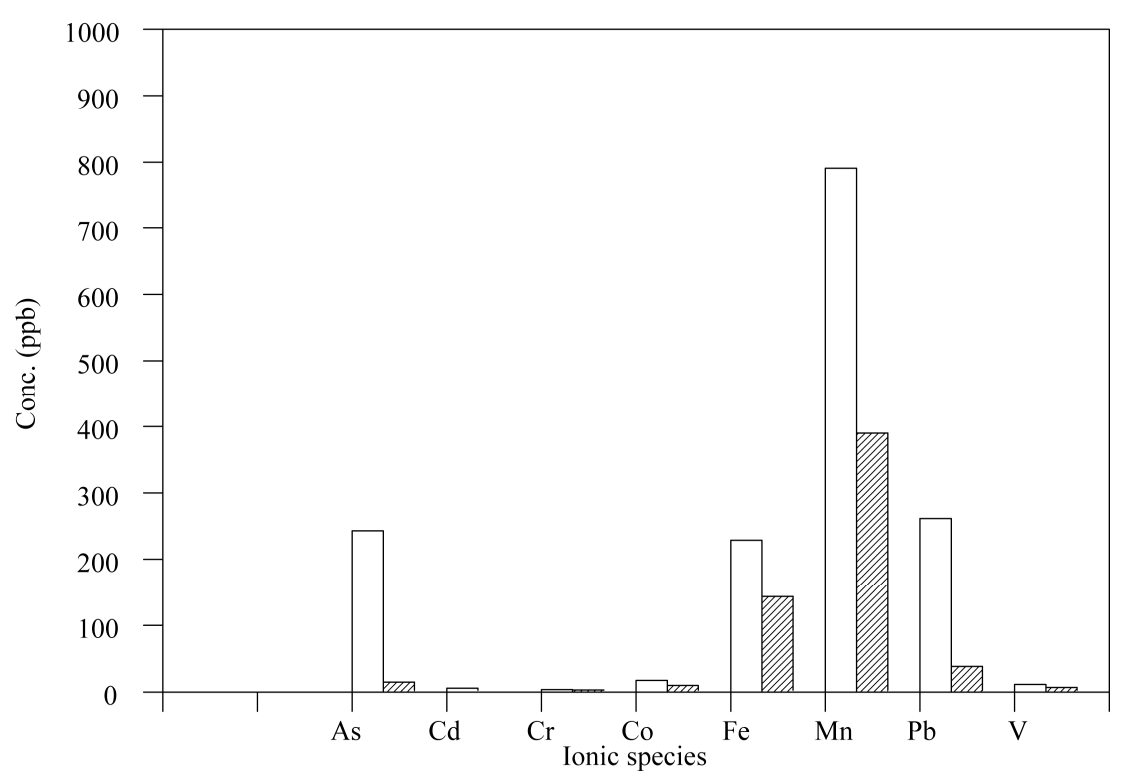

Figure 8. Conc. of As, Cd, Cr, Co, Fe, Mn, Pb and V (ppb) ionic species at the groundwater sample No. (11), where $\square$ is after and $\mathrm{ZTZ} \triangle \mathrm{is}$ after using the syntheticion exchange material. 
Concentrations of the metal ions are not decreased by the same rate, it depend on many factors such as selectivity and the different in electro-negative charges of the attracting forces between the ions species that dissolved in water and the surface of the solid content of ion exchange resin. The results are with an agreement of other investigations [12,13], many factors are affecting the metal removal percentage by the ion exchange resin, these including:

- Competing ions, the removal of heavy metals decreased by increasing of competing ions in the groundwater samples.

- The ion exchange resin is preferred to the cation has a high valance state, arsenate ions species are completely removed from all groundwater.

- Among ions having the same charge, sorption process is preferred for the ions have the smallest hydrated diameter such as lead ions Therefore, the removal of heavy metals decreased by the following order: $\mathrm{Pb}^{2+}$ $>\mathrm{Cd}^{2+}>\mathrm{Co}^{2+}>\mathrm{Fe}^{2+}>$ and $\mathrm{Mn}^{2+}$ The results are with an agreement of that reported [14].

\section{Conclusions}

This research is concerning with the water quality, a modified dioxaloyl-para-sulphanilamide ion exchange resin was prepared in the laboratory is characterized by the, infra red spectra, $x$-ray diffraction and electronic microscopic, the cation exchange capacity and specific surface area are also performed. Speciation of heavy metals such as; $\mathrm{Cr}, \mathrm{Cd}, \mathrm{Co}$, As, $\mathrm{Mn}, \mathrm{Fe}$ and $\mathrm{Pb}$ in groundwater samples were performed using visual MinteqA2 geochemical code version 2.3. This modified ion exchange resin was found to be a good adsorbent that used for heavy metal removal from groundwater samples.

\section{REFERENCES}

[1] M. Ali and M. Soltan, "The Impact of Three Industrial Effluents on Submerged Aquatic Plants in the River Nile, Egypt,” Hydrobiology, Vol. 340, No. 1-3, 1996, pp. 77-83. doi:10.1007/BF00012737

[2] R. Handy, "Intermitted Exposure to Aquatic Pollutants Assessment, Toxicity and Sub-Lethal Responses in Fish and Invertebrates," Comparative Biochemistry and Physiology C-Pharmacology Toxicology \& Endocrinology, Vol. 107, No. 2, 1994, pp. 171-184.

[3] A. G. M. Osman and W. Kloas, "Water Quality and Hea- vy Metal Monitoring in Water, Sediments and Tissues of the African Catfish Clarias Gariepinus (Burchell, 1822) from the River Nile, Egypt,” Journal of Environmental Protection, Vol. 1, No. 4, 2010, pp. 389-400. doi:10.4236/jep.2010.14045

[4] K. Y. Jang-Soon, Y. Seong-Taek, L. Jong-Hwa, K. SoonOh and J. Ho-Young, "Removal of Divalent Heavy Metals (Cd, $\mathrm{Cu}, \mathrm{Pb}$, And $\mathrm{Zn}$ ) and Arsenic (III) from Aqueous Solutions Using Scoria: Kinetics And Equilibrium Of Sorption,” Journal of Hazardous Materials, Vol. 174, No. 1-3, 2010, pp. 307-313. doi:10.1016/j.jhazmat.2009.09.052

[5] U. Wingenfelder, C. Hansen, G. Furrer and R. Schulin, "Removal of Heavy Metals from Mine Waters by Natural Zeolites," Environmental Science and Technology, Vol. 39, No. 12, 2005, pp. 4606-4613. doi:10.1021/es048482s

[6] I. J. Alinnor, "Adsorption of Heavy Metal Ions from Aqueous Solution by Fly Ash,” Fuel, Vol. 86, No. 5-6, 2007, pp. 835-246. doi:10.1016/j.fuel.2006.08.019

[7] K. D. Maria. "Removal of $\mathrm{Mn}^{2+}$ Ions from Drinking Water Using Clinptilolite-Fe Oxide System,” Water Research, Vol. 40, No. 17, 2006, pp. 3167-3176. doi:10.1016/j.watres.2006.07.013

[8] International Atomic Energy Agency (IAEA), “Application of Ion Exchange Processes for the Treatment of Radioactive Waste and Management of Spent Ion Exchangers,” Technical Report Series (TR), No. 408, 2002.

[9] B. Black, "Methods of Soil Analyses," Mcgraw Hill, Inc., New York, 1972.

[10] The World Health Organization (WHO), "The Guidelines of Drinking Water,” Vienna, 2004.

[11] R. A. Freeze and H. Cherry, "Groundwater," PrenticeHall, New Jersey, 1979.

[12] S. J. Allen and P. A. Brown, "Isotherm Analyses for Single Component and Multicomponent Metal Sorption onto Lignite," Journal of Chemical Technology and Biotechnoloy, Vol. 62, No. 1, 1995, pp. 17-24. doi:10.1002/jctb.280620103

[13] A. Seco, P. Marzal and C. Gabaldon, "Adsorption of Heavy Metals from Aquoues Solutions onto Activated Carbon in Single $\mathrm{Cu}$ and Ni Systems and in Binary $\mathrm{Cu}-\mathrm{Ni}$, $\mathrm{Cu}-\mathrm{Cd}$ and $\mathrm{Cu}-\mathrm{Zn}$ Systems," Journal of Chemical Technology and Biotechnoloy, Vol. 68, No. 1, 1997, pp. 23-30. doi:10.1002/(SICI)1097-4660(199701)68:1<23::AID-JCT B595>3.0.CO;2-N

[14] International Atomic Energy Agency, "Waste Treatment and Immobilization Techniques Involving Inorganic Sorbents,” IAEA-TECDOC-947, Vienna, 1997. 